\title{
DER AZIATISCHE KUNST
}

NIEUWS VAN EN VOOR DE VERENIGING - VOORJAAR 2013

\section{- VERZAMELAARSVERENIGINGEN}

In het kwartaalblad ORIGINE, met aandacht voor kunst, antiek en design, is sinds november 2012 de serie 'Verenigingen van verzamelaars' opgenomen. ORIGINE plaatste in haar eerste nummer van 2013,een artikel over de VVAK. Voor deze reportage vond medio december in het Rijksmuseum een gesprek plaats van de Stichting KunstPedia voor ORIGINE met Jan Maarten Boll, VVAK-voorzitter, Rosalien van der Poel, secretaris van de vereniging, Taco Dibbits, directeur Collecties van het Rijksmuseum, en Menno Fitski, conservator Oost-Aziatische kunst en coördinator van de inrichting van het Aziatisch Paviljoen. ORIGINE is te koop in de reguliere tijdschriften- en/of boekhandel.

- PAVILJOENDAGEN 2013 (11 \& 12 oktober 2013)

In de Paviljoencommissie wordt op dit moment hard gewerkt het Aziatisch bedrijfsleven in Nederland in kaart te brengen en - omgekeerd - een overzicht te krijgen van belangrijke Nederlandse bedrijven in de Aziatische landen. Er wordt een Engelstalige flyer gemaakt om potentiële deelnemers aan de Paviljoendagen te interesseren voor het fundraising dinner, op vrijdag 11 oktober in de sfeervolle voorhal van het Rijksmuseum. Contact en info Paviljoendagen: Eline van den Berg (zie contactgegevens hieronder).

\section{- NIEUWSBRIEF EN WEBSITE}

De VVAK-Nieuwsbrief verschijnt ook in 2013 vier keer per jaar en is via www.vvak.nl als pdf te downloaden. Leden die de Nieuwsbrief in papieren vorm willen blijven ontvangen, kunnen dit aangeven.

\footnotetext{
- MEER INFORMATIE EN AANMELDING ACTIVITEITEN

Eline van den Berg - VVAK

p/a Rijksmuseum

Postbus 74888 E: secretariaat@vvak.nl

1070 DN Amsterdam I: www.vvak.nl
} 


\section{Vereniging van Vrienden der Aziatische Kunst}

www.vvak.nl

\section{Erelid}

Dr. J. Fontein

\section{Bestuur}

Mr. J.M. Boll, voorzitter

Ir. A.A. Holst, lid

Mw. drs. R.H.M. van der Poel, secretaris

Mw. drs. R.E. Roskam, lid

Drs. T.T. Wen, penningmeester

\section{Raad van Advies}

Mr. W.L.J. Bröcker

Prof.dr. C.J.A. Jörg

Drs. H.E. Kreijger

Mr. E.M.W. de Lange

Mr. drs. A. Ott

J. Polak

Mw. dr. C.E. van Rappard-Boon

J.J.N. Rost Onnes

Mw. dr. R.L. Steenbergen

\section{Corporate member / Sponsor}

Ottema-Kingma Stichting Leeuwarden

International Institute for Asian Studies (IIAS)

\section{Lidmaatschap}

- Gewoon lidmaatschap: $€ 60$,- per kalenderjaar

- Gewoon lidmaatschap (inclusief partner): $€$ 90,- per kalenderjaar

- Jongerenlidmaatschap ( $\mathrm{t} / \mathrm{m} 25$ jaar): $€$ 25,- per kalenderjaar

- Sponsor/corporate member:

(tenminste) $€ 600,-$ per kalenderjaar

Het lidmaatschap van de Vereniging loopt van 1 januari tot en met 31 december. Opzegging van het lidmaatschap kan alleen schriftelijk via het bestuur (vvak@denboerenvink.nl). Opzegging voor een komend jaar dienen vóór 31 december van het lopende jaar door het bestuur ontvangen te zijn. Wanneer het lidmaatschap in de loop van het verenigingsjaar wordt beëindigd, blijft de bijdrage voor het hele jaar verschuldigd.

\section{Als WAK-lid}

- ontvangt u het tijdschrift Aziatische Kunst

- blijft u goed op de hoogte van tentoonstellingen, beurzen en veilingen op het gebied van Aziatische kunst

- wordt u uitgenodigd voor lezingen en speciale bijeenkomsten

- krijgt u een lidmaatschapskaart, waarmee u gratis toegang heeft tot het Rijksmuseum Amsterdam

\section{Ledenadministratie}

Jac's den Boer en Vink bv

Postbus 43 - 2850 AA Haastrecht

T: 0182501696

E:vvak@denboerenvink.nl

\section{Secretariaat WVAK \\ Eline van den Berg \\ p/a Rijksmuseum}

Postbus 74888 - 1070 DN Amsterdam

E: secretariaat@vvak.nl

\section{Advertenties}

Om te adverteren in Aziatische Kunst kunt $\mathbf{u}$ contact opnemen met de heer drs. T.T. Wen, penningmeester, e-mail: wentt@xs4all.nl

\section{Bankrekeningnummer}

ING 188285 , ten name van Vereniging van Vrienden der Aziatische Kunst, Den Haag.

\section{Kamer van Koophandel}

De Vereniging is ingeschreven bij de Kamer van Koophandel in Amsterdam, onder nummer 40.531.260.

\section{ANBI}

De Vereniging heeft de status van een Algemeen Nut Beogende Instelling. 